\title{
Psychophysiological activity and reactivity and concept identification performance in alcoholics and controls
}

\author{
JOHN T. BRAGGIO and VLADIMIR PISHKIN \\ Department of Veterans Affairs Medical Center, University of Oklahoma Health Sciences Center, \\ and Willow View Hospital, Oklahoma City, Oklahoma
}

\begin{abstract}
Detoxified alcoholics and controls were tested on the Concept Identification (CI) task as seven measures of psychophysiological activity and reactivity were recorded. On the CI task, subjects initially learned, by trial and error, to classify geometric patterns until the criterion of 16 consecutive correct responses was reached in 80-160 trials. Fewer alcoholics solved the CI problem than did controls. While working on the CI problem, alcoholics had higher skin conductance level (SCL) and vasomotor (VM) activity than controls. Only alcoholics had significant negative correlations between SCL and VM activity. Also, alcoholics who did not solve the problem had significant negative correlations between response latency and systolic blood pressure. The alcoholics' abstraction deficit and their sensitivity to failure could explain why they had more psychophysiological activity on the CI problem than did controls.
\end{abstract}

Alcoholics demonstrate greater neuropsychological deficits than controls (Goldman, 1986; Parsons \& Farr, 1981). Even though alcoholics have abstracting deficits (Parsons \& Farr, 1981), Pishkin, Fishkin, and Stahl (1972) did not find differences between alcoholics and controls on the Concept Identification (CI) task, a laboratory measure of rule learning. Two reasons could explain their negative outcome: first, they used an easy CI problem. Second, they included only alcoholics who solved the CI problem. Nonetheless, Pishkin et al. (1972) reported that controls had more "extreme" galvanic skin responses (GSRs) than alcoholics. The purpose of this study was to test alcoholics and controls using a more difficult CI problem than was used by Pishkin et al. (1972), while measures of psychophysiological activity and reactivity were recorded. Also, we did not exclude alcoholics who failed to solve the CI problem.

\section{METHOD}

\section{Subjects}

A total of 54 male alcoholics and 26 controls were tested. The two groups were matched in age $\left(M_{\mathrm{A}}=40.9, M_{\mathrm{C}}=38.9\right)$, education $\left(M_{\mathrm{A}}=13.1\right.$, $\left.M_{\mathrm{C}}=13.6\right)$, and Shipley Vocabulary Age $\left(M_{\mathrm{A}}=17.1, M_{\mathrm{C}}=17.5\right)$,

This paper was presented at the annual meeting of the Society for Psychophysiological Research, San Francisco, CA, October 19-23, 1988. This research was supported by VA medical research funds, Department of Veterans Affairs and Oklahoma Health Research Contract 3608. The authors want to express their appreciation to William R. Lovallo, Director, Behavioral Sciences Laboratories, Veterans Affairs Medical Center, for his numerous contributions, which facilitated the completion of this study, and to Cynthia Sabouri for typing the manuscript. Send reprint requests to John T. Braggio, Behavioral Sciences Laboratories (151A), Department of Veterans Affairs Medical Center, 921 N.E. 13th St., Oklahoma City, OK 73104.
Six months prior to testing, the average daily intake of ethanol was $14.02 \mathrm{oz}$ for the alcoholics and $.71 \mathrm{oz}$ for the controls. The alcoholics' average chronicity of alcoholism was $\mathbf{1 4 . 2}$ years. The alcoholics were patients in the 28-day program of the Alcohol Rehabilitation Unit, Oklahoma City Veterans Affairs Medical Center. They had a DSM-III diagnosis of alcohol dependence (American Psychiatric Association, 1980).

\section{Procedure}

After the subject signed the consent form, he was asked to sit in a padded chair, and psychophysiological recording leads were attached. Electromyogram (EMG) activity was recorded from the forehead directly above the frontalis muscles; skin conductance level (SCL) was recorded from the palmar surface of the second and fourth fingers of the left hand; a V-lock cuff was placed over the brachial artery of the left arm to record systolic blood pressure (SBP), diastolic blood pressure (DBP), mean arterial pressure (MAP), and heart rate (HR). Vasomotor (VM) activity was recorded by placing a photoelectric plethysmograph unit on the thumb of the left hand

The subjects were tested using an automated CI and physiological recording system described in a recent publication (Pishkin, Braggio, \& Lovallo, 1987). This system included amplifiers that were used to record EMG, SCL, and VM activity, and an automated blood pressure unit.

Each volunteer faced a ground-glass rear-projection screen. Below the screen there were two response buttons labeled + and - . Above each button there was one feedback light. On each trial of the CI problem, the subject had to classify a geometric stimulus pattern by using one or both attributes. The attributes used were "small and/or square." The CI attribute-identification problem was based on the inclusive disjunctive rule (Haygood \& Bourne, 1965). When either or both attributes were present, the slide was considered an example of the concept, and the subject had to push the + button. To respond correctly when neither attribute was present, the subject had to push the - button. After the subject made his response, the appropriate feedback light was illuminated for $2 \mathrm{sec}$, thereby indicating the correct classification of the slide and if the response was correct.

The experiment was divided into three phases: a 20-min pre-test baseline (Phase I), the presentation of two CI problems (Phase II), and a 5-min posttest baseline (Phase III). For this study, only the second CI problem was analyzed. To solve the CI problem, the subject had to be correct on 16 consecutive trials. Psychophysiological activity measures were recorded during all three phases. 
Table 1

Differences in Psychophysiological Activity Between Alcoholics and Controls on the Concept Identification Task

\begin{tabular}{|c|c|c|c|c|c|c|c|c|}
\hline \multirow{2}{*}{$\begin{array}{c}\text { Dependent } \\
\text { Variables } \\
\end{array}$} & \multirow[b]{2}{*}{ Group (G) } & \multicolumn{3}{|c|}{ Phase of Testing ( $p)$} & \multirow{2}{*}{$\begin{array}{l}\text { Group } \\
\text { Means }\end{array}$} & \multicolumn{3}{|c|}{ Fs and Ps } \\
\hline & & Baseline & Test & Posttest & & $\mathbf{G}$ & $\mathbf{P}$ & $G \times P$ \\
\hline SCL & $\begin{array}{l}\text { ALC } \\
\text { CONT }\end{array}$ & $\begin{array}{l}285.42 \\
141.50\end{array}$ & $\begin{array}{l}409.29 \\
202.82\end{array}$ & $\begin{array}{l}380.37 \\
194.94\end{array}$ & $\begin{array}{l}358.36 \\
179.75\end{array}$ & 2.91 & $35.77 \dagger$ & $3.77^{*}$ \\
\hline VM & $\begin{array}{l}\text { ALC } \\
\text { CONT }\end{array}$ & $\begin{array}{l}8.33 \\
7.70\end{array}$ & $\begin{array}{l}7.68 \\
6.24\end{array}$ & $\begin{array}{l}7.81 \\
6.10\end{array}$ & $\begin{array}{l}7.87 \\
6.57\end{array}$ & 3.34 & $13.28 \dagger$ & 2.49 \\
\hline EMG & $\begin{array}{l}\text { ALC } \\
\text { CONT }\end{array}$ & $\begin{array}{l}348.32 \\
368.50\end{array}$ & $\begin{array}{l}539.30 \\
499.17\end{array}$ & $\begin{array}{l}419.91 \\
438.81\end{array}$ & $\begin{array}{l}435.84 \\
435.49\end{array}$ & $<1$ & $20.47 \dagger$ & $<1$ \\
\hline HR & $\begin{array}{l}\text { ALC } \\
\text { CONT }\end{array}$ & $\begin{array}{l}73.86 \\
68.39\end{array}$ & $\begin{array}{l}77.09 \\
71.97\end{array}$ & $\begin{array}{l}74.97 \\
69.69\end{array}$ & $\begin{array}{l}75.31 \\
70.02\end{array}$ & $4.31^{*}$ & $32.34 \dagger$ & $<1$ \\
\hline SBP & $\begin{array}{l}\text { ALC } \\
\text { CONT }\end{array}$ & $\begin{array}{l}123.47 \\
123.45\end{array}$ & $\begin{array}{l}127.26 \\
127.84\end{array}$ & $\begin{array}{l}124.92 \\
125.77\end{array}$ & $\begin{array}{l}125.21 \\
125.68\end{array}$ & $<1$ & $23.75 \dagger$ & $<1$ \\
\hline DBP & $\begin{array}{l}\text { ALC } \\
\text { CONT }\end{array}$ & $\begin{array}{l}77.77 \\
81.33\end{array}$ & $\begin{array}{l}82.86 \\
84.78\end{array}$ & $\begin{array}{l}78.68 \\
82.44\end{array}$ & $\begin{array}{l}79.77 \\
82.85\end{array}$ & 1.57 & $7.85 \dagger$ & $<1$ \\
\hline MAP & $\begin{array}{l}\text { ALC } \\
\text { CONT }\end{array}$ & $\begin{array}{l}93.13 \\
95.01\end{array}$ & $\begin{array}{l}96.70 \\
98.49\end{array}$ & $\begin{array}{l}93.95 \\
96.87\end{array}$ & $\begin{array}{l}94.59 \\
96.79\end{array}$ & $<1$ & $19.56 \dagger$ & $<1$ \\
\hline
\end{tabular}

Note-SCL = skin conductance level, VM = vasomotor activity, EMG = electromyogram, HR = heart rate, $\mathrm{SBP}=$ systolic blood pressure, $\mathrm{DBP}=$ diastolic blood pressure, and MAP = mean arterial pressure; $\mathrm{ALC}=$ alcoholics, CONT $=$ controls. $\quad{ }^{*} p<.05 . \quad t_{p}<.01$.

\section{RESULTS}

Fewer alcoholics than controls solved the $\mathrm{CI}$ problem $\left[\chi^{2}(1)=3.043, p=.08\right]$. However, the two groups did not differ in incorrect responses and response latency ( $p>.05$, for each comparison). The psychophysiological data were analyzed using a group (alcoholics, controls) $\times$ phase of testing (I-III) analysis of variance design (Winer, 1971). These data are shown in Table 1. Alcoholics had significantly higher HRs than controls $(p<.05)$. The phase of testing factor was significant for all seven psychophysiological measures (all $p \mathrm{~s}<.01$ ). Work on the CI problem produced significant changes from baseline in EMG, HR, SBP, DBP, and MAP (all $p s<.05)$. The interaction was significant for SCL $(p<.05)$. Alcoholics had significant increases in SCL from baseline to CI problem and to posttest baseline (both ps < .01). Controls showed significant increases in SCL from baseline to CI problem and to posttest baseline $(p s<.01)$. While the alcoholics had a higher CI problem-produced increase in SCL than was found for controls, this group difference was not significant. Therefore, these results demonstrate that alcoholics do not differ from controls in psychophysiological reactivity produced by work on a cognitive problem.

Correlations between measures of psychophysiological activity and CI performance were computed. Only alcoholics showed significant negative correlations between total incorrect responses and SCL $\left[r_{\mathrm{xy}}(52)=-.287\right.$, $p<.05]$ and VM activity $\left[r_{\mathrm{xy}}(52)=-.282, p<.05\right]$. The controls had a significant positive correlation between total incorrect responses and EMG activity $\left[r_{\mathrm{xy}}(24)=\right.$ $.535, p<.01]$. In addition, the alcoholics who did not solve the CI problem showed significant negative correlations between response latency and SBP $\left[r_{\mathrm{xy}}(32)=\right.$ $-.446, p<.01]$ and MAP $\left[r_{\mathrm{xy}}(32)=-.386, p<.05\right]$.

\section{DISCUSSION}

This study showed that alcoholics are impaired in solving an attribute identification $\mathrm{CI}$ problem that was formed by using the inclusive disjunctive rule. Fewer alcoholics than controls solved the $\mathrm{CI}$ problem. Pishkin, Lovallo, and Bourne (1985) demonstrated that alcoholics made more errors than controls when they were tested using three rule-learning CI problems based on the inclusive disfunction rule. This study and the Pishkin et al. (1985) experiment have shown that the alcoholics' deficit also includes impaired attribute identification and rule learning on the CI task if an inclusive disjunctive rule is used. CI rules that are less difficult will not tap the alcoholics' abstracting deficit. Since Pishkin et al. (1972) did not find differences between alcoholics and controls when alcoholics who did not solve the $\mathrm{CI}$ problem were excluded from the analyses of the group data, it is possible that some alcoholics do not demonstrate rule-learning deficits. Parsons (1987) found that only about $70 \%$ of alcoholics showed deficits on neuropsychological tests. By using the $\mathrm{CI}$ task and neuropsychological tests, it could be possible to identify alcoholics who either show or do not show impaired cognitive performance.

Another contribution of this study was the finding that work on the CI problem produced more psychophysiological activity in alcoholics than in controls. The higher levels of psychophysiological activity in alcoholics could have been due to two factors: First, the CI problem could have been functionally more difficult for the alcoholics than for the controls (the alcoholics had to work harder than the controls on the CI problem). As a consequence, the alcoholics became psychophysiologically more active than the controls. Second, the alcoholics could have been more psychophysiologically active whenever they made errors on the $\mathrm{CI}$ task. We found significant negative correlations between incorrect responses and VM activity and SCL and between response latency and SBP and MAP. Future research should specify how rule difficulty and failure differentially influence $\mathrm{CI}$ performance and psychophysiological activity in alcoholics and in controls.

\section{REFERENCES}

American Psychiatric Association (1980). Diagnostic and statistical manual of mental disorders (3rd ed.). Washington, DC: American Psychiatric Association.

Goldman, M. S. (1986). Neuropsychological recovery in alcoholics: Endogenous and exogenous processes. Alcoholism: Clinical \& Experimental Research, 10, 136-144. 
Haygood, R. C., \& Bourne, L. E., JR. (1965). Attribute- and rulelearning aspects of conceptual behavior. Psychological Review, 72, 175-195.

Parsons, O. A. (1987). Intellectual impairment in alcoholics: Persistent issues. Acta Medica Scandinavica, Supplement No. 717, 33-46.

PArsons, O. A., \& FARR, S. P. (1981). The neuropsychology of alcohol and drug use. In S. B. Filsov and T. J. Boll (Eds.), Handbook of clinical neuropsychology (pp. 320-365). New York: Wiley.

Pishkin, V., Braggio, J. T., \& Lovallo, W. R. (1987). Physiological responses of Type $A$ and Type B men during cognitive performance. Journal of Clinical Psychology, 43, 309-318.
Pishkin, V., Fishkin, S., \& Stahl, M. L. (1972). Concept learning in chronic alcoholics: Psychophysiological and set functions. Journal of Clinical Psychology, 28, 328-334.

Pishkin, V., Lovallo, W. R., \& Bourne, L. C., JR. (1985). Chronic alcoholism in males: Cognitive deficit as a function of age of onset, age, and duration. Alcoholism: Clinical \& Experimental Research, 9. 400-406.

WINER, B. J. (1971). Statistical principles in experimental design (2nd ed.). New York: McGraw-Hill.

(Manuscript received February 27, 1991.)

\title{
Notices and Announcements
}

\author{
32nd Annual Meeting of the Psychonomic Society \\ San Francisco, California \\ November 22-24, 1991
}

The 32nd Annual Meeting of the Psychonomic Society will be held in San Francisco, November 22-24, 1991. The meetings will begin Friday morning and continue until Sunday at noon. The headquarters hotel will be the Hyatt Regency San Francisco at Embarcadero Center.

The call for papers was mailed to members and associates in April, with a June 21 deadline for submissions.

The program and hotel reservation cards will be mailed to members and associates in September. A copy of the program will be published in the November issue of the Bulletin of the Psychonomic Society.

For further information, please contact the secretary-treasurer of the Society: Cynthia H. Null, P.O. Box 7104, San Jose, California 95150-7104 (telephone: 415-604-1260). 